\title{
Vitamin B12 Status and Its Association with Helicobacter pylori Infection in Alcohol Dependent Patients
}

\author{
Martijn G.H. vaN OIJEN ${ }^{1}$, Robert J.F. LAHEI ${ }^{1}$, Cor A.J. DE JONG ${ }^{2}$, \\ Wilbert H.M. PETERS ${ }^{1}$ and Jan B.M.J. JANSEN ${ }^{1}$

\begin{abstract}
${ }^{1}$ Department of Gastroenterology, University Medical Center St. Radboud, Nijmegen, The Netherlands ${ }^{2}$ Novadic-Network for Addiction Treatment Services/Institute for Scientists-Practitioners in Addiction, University of Nijmegen, The Netherlands
\end{abstract}

(Received January 26, 2004)

\begin{abstract}
Summary Both infection with Helicobacter pylori and alcohol abuse have been associated with low vitamin B12 serum levels. The interaction between both risk factors is unknown. The aim of this study was to determine whether Helicobacter pylori infection is associated with low vitamin B12 levels in alcohol dependent patients. Blood samples were obtained from adult alcohol dependent patients undergoing detoxification and analyzed for serum vitamin B12 levels. Helicobacter pylori infection was serologically measured. Patient characteristics, medication use and alcohol consumption at admission were assessed by interview. A total of 6 out of 89 patients included presented low vitamin B12 levels, all were sub clinical deficient $(<250 \mathrm{pmol} / \mathrm{L})$ and none were clinical deficient $(<150 \mathrm{pmol} / \mathrm{L})$. Infection with Helicobacter pylori was present in $29 \%$ of the patients. The average vitamin B12 levels in Helicobacter pylori seropositive and seronegative patients were $1,033 \mathrm{pmol} / \mathrm{L}$ (SD 741) and $971 \mathrm{pmol} / \mathrm{L}$ (SD 717), respectively. The relation between Helicobacter pylori infection and vitamin $\mathrm{B} 12$ deficiency was not of significance $(\mathrm{OR}=0.48$; 95\% CI [0.05-4.32]). In conclusion, Helicobacter pylori infection is not a risk factor for low vitamin B12 levels in alcohol dependent patients.
\end{abstract}

Key Words vitamin B12, Helicobacter pylori, alcohol

Helicobacter pylori infection and excessive alcohol consumption can be harmful for the stomach and the ileum in the development of gastritis or peptic ulcera (1, 2). Both factors seem also associated with vitamin B12 deficiency. The results from a recent study from ShuvalSudai et al. show a higher prevalence of Helicobacter pylori infection among subjects with serum vitamin B12 levels that are within the lower end of the normal range (3). An explanation for this association can be found in the complex absorption of vitamin B12, in which the stomach plays an important role: pepsin and gastric acid, both secreted in the stomach, liberate vitamin B12 from its protein binding in diet. Gastric parietal cells in the stomach release intrinsic factor (IF). Only after binding to this factor, the IF-B12-complex can be absorbed by receptors in the terminal ileum. Helicobacter pylori interferes with this process which might explain low serum vitamin B12 levels in patients with this infection (3-6). The interference consists of irritation of the mucosal layer in the stomach, wherefore the parietal cells may not be able to release as much intrinsic factor as in patients without Helicobacter pylori induced gastritis.

The relation between alcohol consumption and vitamin B12 is controversial $(7-10)$. Lower serum levels have been associated to alcohol abuse. In 1985 Kanazawa and Herbert showed that plasma vitamin

E-mail: M.vanOijen@mdl.umcn.nl
B12 levels are significantly higher in alcohol dependent patients than in non-drinkers (7). However, in another study no association between alcohol abuse and vitamin B12 was found $(9,10)$. The difference in outcome between the studies might be a result of interference of other risk factors, such as infection with Helicobacter pylori. In none of these studies the influence of Helicobacter pylori was taken into consideration. Therefore the aim of this study is to determine whether Helicobacter pylori infection is associated with vitamin B12 levels in alcohol dependent patients.

\section{METHODS}

Consecutive patients were recruited between January and November 2002 at 4 different detoxification clinics in the Netherlands. Patients were included if they had reached the age of 18 and were alcohol dependent following DSM-IV criteria. Patients were asked to participate at the first day of admission before the detoxification process, consisted of total controlled alcohol abstinence, has started. After written informed consent, blood samples were taken at the start of detoxification and stored at $-20^{\circ} \mathrm{C}$. Furthermore, demographics, alcohol consumption, smoking habits and medication use at admission were reported by interview. Procedures used in human subjects were in accordance with the ethical standards of the responsible committee on human experimentation (institutional or regional) and with the Helsinki Declaration of 1975 , as revised in 
1983.

Assays of plasma vitamin B12 and Helicobacter pylori antibodies were performed in a hospital laboratory. Samples were run at the same time to minimize assay variability. The Immulite analyzer was used for the quantitative measurement of vitamin B12 serum levels. Vitamin B12 levels $<150 \mathrm{pmol} / \mathrm{L}$ were classified as clinical deficiency, between $150-250 \mathrm{pmol} / \mathrm{L}$ as sub clinical deficiency and above $250 \mathrm{pmol} / \mathrm{L}$ as normal.

Testing for antibodies against Helicobacter pylori infection was performed with a commercially available enzyme-linked immunosorbent assay (ELISA) (Pyloriset, Orion Diagnostics, Finland). The specific antibodies against Helicobacter pylori infection, measured in the serum samples, were classified according to the manufacturer's instructions. Patients were considered to be Helicobacter pylori seropositive when values were above 20 EIU.

Data were analyzed using SAS statistical software (version 8.0). Chi-square and $t$-test statistics were used to estimate differences in the baseline characteristics among patients with and without vitamin B12 defi-

Table 1. Baseline characteristics of the study population.

\begin{tabular}{llr}
\hline \multicolumn{1}{c}{ Baseline characteristics } & \\
\hline Male/female (no.) & & $69 / 20$ \\
Mean age (y) & & 42 \\
Vitamin B12 deficient (\%) & 7 \\
H. pylori seropositive (\%) & & 29 \\
Beverage use (\%) & Beer & 98 \\
& Wine & 13 \\
Mean alcohol intake (g/d) & Liquor & 8 \\
Mean addiction duration (y) & & 139 \\
Previous detoxification (\%) & & 17 \\
Current smoking (\%) & & 78 \\
Co-addiction (\%) & Cannabis & 25 \\
& Cocaine & 23 \\
& Opiates & 12 \\
\hline
\end{tabular}

ciency. Fisher's exact test was used where appropriate. Logistic regression analysis was performed to study the association between infection with Helicobacter pylori and vitamin B12 levels to estimate an Odds Ratio with 95\% Confidence Intervals (CI) for these variables. Multiple regression analysis was performed to adjust for alcohol consumption and smoking habits.

\section{RESULTS}

We included 89 alcohol dependent patients, all Caucasians: 64 males, an average age of 42 years (Table 1). The patients reported an average addiction period of more than $15 \mathrm{y}$ and an average daily ethanol consumption of $140 \mathrm{~g}$ or more. Most patients $(87 \%)$ were currently smoking and $78 \%$ underwent detoxification before. Patients often used to have co-addictions, where cannabis and cocaine use was most frequently present.

A low serum B12 level $(<250 \mathrm{pmol} / \mathrm{L})$ was found in a total of 6 out of 89 patients ( $7 \%$ ). All deficient patients were sub clinical $(150-250 \mathrm{pmol} / \mathrm{L})$, none of them were clinical vitamin B12 deficient ( $<150 \mathrm{pmol} / \mathrm{L})$. All other patient characteristics were similar between patients with and without vitamin B12 deficiency (Table 2). In 84 out of 89 patients included we were able to assess infection with Helicobacter pylori, $29 \%$ of the patients

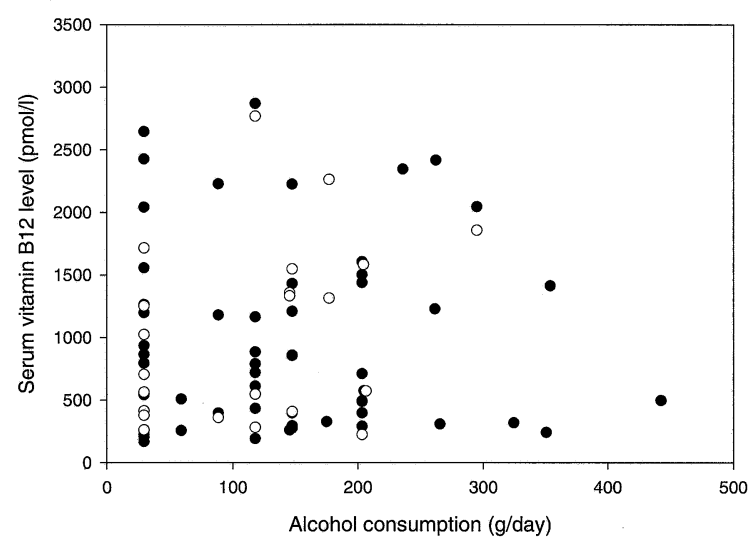

Fig. 1. Alcohol consumption and vitamin B12 serum levels for Helicobacter pylori seropositive and seronegative patients. $\bullet, H$. pylori negative; $\bigcirc, H$. pylori positive.

Table 2. Frequency of possible risk factors for B12 deficiency.

\begin{tabular}{|c|c|c|c|c|c|c|}
\hline & \multirow{2}{*}{ Vitamin B12 } & \multicolumn{2}{|c|}{ Deficiency } & \multicolumn{2}{|c|}{ No deficiency } & \multirow{2}{*}{$\begin{array}{l}\text { Differences } \\
\text { OR }(95 \% \text { CI })\end{array}$} \\
\hline & & $N=6$ & $(\%)$ & $N=83$ & $(\%)$ & \\
\hline \multirow[t]{2}{*}{ Gender } & M & 5 & $(83)$ & 64 & $(77)$ & $1.53(0.17-13.92)$ \\
\hline & $\mathrm{F}$ & 1 & (17) & 19 & (23) & \\
\hline \multirow[t]{2}{*}{ Age (y) } & $\leq 40$ & 2 & (33) & 33 & $(40)$ & $1.32(0.23-7.62)$ \\
\hline & $>40$ & 4 & (67) & 50 & (60) & \\
\hline \multirow[t]{2}{*}{ H. pylori } & Pos & 1 & (17) & 24 & (29) & $0.48(0.05-4.32)$ \\
\hline & $\mathrm{Neg}$ & 5 & (83) & 59 & (71) & \\
\hline \multirow[t]{2}{*}{ Smoking } & Yes & 3 & (50) & 45 & (54) & $0.84(0.16-4.43)$ \\
\hline & No & 3 & $(50)$ & 38 & $(46)$ & \\
\hline \multirow[t]{2}{*}{ Alcohol intake (g/d) } & $\leq 120$ & 4 & (67) & 43 & (52) & $0.55(0.10-3.18)$ \\
\hline & $>120$ & 2 & (33) & 40 & $(48)$ & \\
\hline
\end{tabular}


were Helicobacter pylori seropositive (Table 1). One out of six alcohol dependent patients with low vitamin B12 levels $(<250 \mathrm{pmol} / \mathrm{L})(17 \%)$ was Helicobacter pylori seropositive in comparison to 5 being seronegative (83\%). In the non vitamin B12 deficient group $(>250 \mathrm{pmol} / \mathrm{L})$ this proportion was $29 \%$ and $71 \%$, respectively. The relation between Helicobacter pylori infection and vitamin B12 deficiency was not of significance $(\mathrm{OR}=0.48 ; 95 \%$ CI $[0.05-4.32])$. The average serum vitamin B12 levels of Helicobacter pylori infected and not infected patients was 1,033 (SD 741) and $971 \mathrm{pmol} / \mathrm{L}$ (SD 717), respectively. The average alcohol consumption of vitamin B12 deficient patients $(<250$ $\mathrm{pmol} / \mathrm{L})$ did not differ with non-deficient patients $(>250 \mathrm{pmol} / \mathrm{L})$, alcohol consumption were 127 and $134 \mathrm{~g} / \mathrm{d}(p>0.5)$, respectively (Fig. 1). In this figure the alcohol dependent patients were subdivided into Helicobacter pylori infected and non-infected, but it showed no difference between both groups.

\section{DISCUSSION}

There is controversy whether alcohol dependent patients have decreased or increased serum vitamin B12 levels. In our study population vitamin B12 deficiency was not very common. All found serum vitamin B12 deficiencies were between 150 and $250 \mathrm{pmol} / \mathrm{L}$, which indicates a sub clinical deficiency. Clinical relevant deficiencies were not found in our population. Although Helicobacter pylori infection was not associated with a sub clinical deficiency, the vitamin B12 levels were higher in Helicobacter pylori seropositive patients. This association is however not clinical relevant due to the high vitamin B12 levels found.

In contrast to the results of this study, other studies showed low vitamin B12 levels in alcohol dependent patients. The difference in these findings could be explained by the way in which vitamin B12 were assessed. In a systematic review exploring vitamin B12 status and chronic alcoholism, Cravo et al. report vitamin B12 assessments in serum and plasma, with respectively lower and higher levels (10). There were not given insights in the way of analysis, but an explanation for this difference could be that frozen plasma samples become a turbid suspension after defrosting. This causes a false increased vitamin B12 level up to $50 \%$ when assessed in an immunochemical way. Another reason for the differences might be the type of beverage consumed by the studied alcohol abusing population. In our Dutch population the reported alcohol consumption consisted mostly of beer, which contains more vitamin B12 than other beverages. Moreover, the prevalence of the use of vitamin preparations use in the Dutch population is increasing (11). However, none of the alcoholics in our study used a vitamin supplement which might have increased vitamin B12 levels.

Vitamin B12 metabolism is complicate, several organs are involved. Vitamin B12 deficiency, assessed as low circulating concentrations, is thought to be less common in chronic alcoholics, probably because of large stores of vitamin B12 in the liver. In general, it is known that vitamin B12 concentration decreases in hepatic tissues of patients with liver disorders. This hepatic vitamin B12 concentration is affected not only by alcohol consumption, but also by other dietary conditions, such as unbalanced diet and lack of ingesting vitamin B12 rich foods. Therefore the serum vitamin B12 concentration changes according to the condition of the liver disorder due to alcohol abuse. Nonetheless, tissue deficiencies of this vitamin may occur despite subnormal, normal, or even high circulating concentrations. Kanazawa and Herbert showed that plasma vitamin B12 levels are significantly higher in alcohol dependent patients than in non-drinkers (7). However, analysis of liver biopsies demonstrated that vitamin B12 concentrations in liver tissue were significantly lower in alcohol dependent patients than in non-drinkers, thus implying that chronic alcohol intake may impair the uptake or retention of this vitamin by the liver and perhaps by other peripheral tissues as well.

In the study of Gloria et al. vitamin B12 in serum was higher in the alcoholic group than in the non-alcoholic group (9). This observation might be a reflection of poor retention of this vitamin by the peripheral tissue as previously implicated by Kanazawa and Herbert.

In conclusion, vitamin B12 deficiency was not very common in alcohol dependent patients. As a result we did not find an association between Helicobacter pylori infection and serum vitamin B12 deficiency in alcohol dependent patients. Infection with Helicobacter pylori is not a risk factor for low serum vitamin B12 levels in alcohol dependent patients.

\section{Acknowledgments}

We specially thank the four detoxification clinics with the cooperated physicians that participated in this study: Paschalis Venray (T. Wijdeveldt MD, P. Michielsen MD), de Grift Arnhem/Nijmegen (K. de Rijk MD, C. van Ojen MD), Tactus Enschede/Zutphen (H. de Haan MD, P. Bangsma MD) and Novadic St.Oedenrode (C. de Jong MD, A. van Hoek MD).

\section{REFERENCES}

1) Lieber CS, Flier JS, Underhill LH. 1995. Medical disorders of alcoholism. NEJM 333: 1058-1065.

2) Bujanda L. 2000. The effects of alcohol consumption upon the gastrointestinal tract. Am J Gastroenterol 95: 3374-3381.

3) Shuval-Sudai O, Granot E. 2003. An association between $H$. pylori infection and serum vitamin B12 levels in healthy adults. J Clin Gastroenterol 36: 130-133.

4) Kaptan K, Beyan C, Ural AU, et al. 2000. H. pylori: Is it a novel causative agent in vitamin B12 deficiency? Arch Int Med 160: 1349-1353.

5) Stopeck A. 2000. Links between H. pylori infection, cobalamin deficiency and pernicious anemia. Arch Int Med 160: 1229-1230.

6) Perez-Perez GI. 1997. Role of H. pylori infection in the development of pernicious anemia. Clin Infect Dis 25: 1020-1022.

7) Kanazawa S, Herbert V. 1985. Total corrinoid, cobalamin (vitamin B12), and cobalamin analogue levels 
may be normal in serum despite cobalamin in liver depletion in patients with alcoholism. Lab Invest 53: 108-110.

8) Halsted CH, Villanueva JA, Devlin AM. 2002. Folate deficiency, methionine metabolism, and alcoholic liver disease. Alcohol 27: 169-172.

9) Gloria L, Cravo M, Camilo ME, et al. 1998. Nutritional deficiencies in chronic alcoholics: Relation to dietary intake and alcoholic consumption. Am J Gastroenterol
93: 665-666.

10) Cravo ML, Camilo ME. 2000. Hyperhomocysteinemia in chronic alcoholism: relations to folic acid and vitamin B6 and B12 status. Nutrition 16: 296-302.

11) van Asselt DZB, de Groot LCPGM, van Staveren WA, et al. 1998. The role of cobalamin intake and atrophic gastritis in mild cobalamin deficiency in older Dutch subjects. Am J Clin Nutr 68: 328-334. 